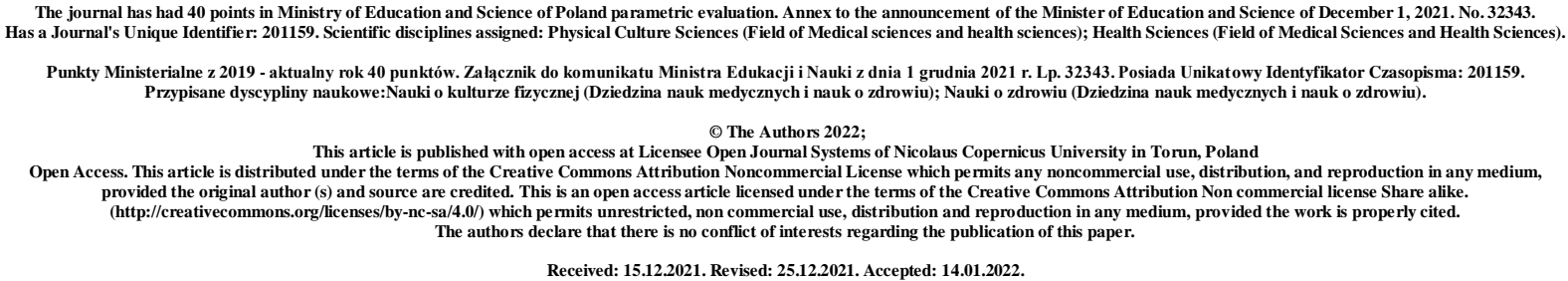

\title{
Influence of latent iron deficiency on cognitive abilities in students
}

\author{
Ali Dani Sheikh, V. V. Babienko, E. V. Kobolev
}

\section{Odessa National Medical University, Odessa, Ukraine}

\section{Abstract}

The aim of the study is to assess the impact of latent iron deficiency on students' cognitive abilities. Material and methods. The study was conducted during 2018-2021 at the Department of Hygiene and Medical Ecology of Odessa National Medical University. A survey of 188 medical students aged 18-20 was conducted using a screening survey. Estimation of the qualitative content of iron compounds in the diet was performed by a calculation method using the USDA / FDA database. Persons with probable iron deficiency were examined for hemoglobin, erythrocytes, hematocrit (general clinical blood test) and serum ferritin. Additionally, the cognitive abilities of people with latent iron deficiency were assessed using MoSA, TMT, GPB, Schulte tables and TAS-20. As a control, 30 students aged 18-20 years who showed no signs of latent or overt iron deficiency were interviewed. Statistical processing was performed by methods of variance and correlation anamnesis using the software Statistica 13.0 (TIBCO, USA). Results. When evaluating diets, probable iron deficiency was identified in $69(36.7 \%)$ students surveyed. A significant number of students reported signs of iron deficiency, namely general weakness (27 or $14.4 \%$ ), increased fatigue (30 cases or $15.9 \%$ ), pale skin and mucous membranes (6 or $3.2 \%$ ), drowsiness ( 8 or $4.3 \%$ ), dry mouth (11 or 5.9\%), brittle hair (4 or $2.1 \%$ ), bleeding gums (3 or $1.6 \%$ ). In isolated cases, hyposmia, dysgeusia and dysphagia have occurred. Probable iron deficiency was found at the 
previous stage of the study in 29 (15.4\%) patients, they subsequently underwent verifying laboratory tests. In the analysis of the obtained data, the diagnosis of mild iron deficiency anemia was confirmed in $2(6.9 \%)$ girls. Latent iron deficiency was identified in $16(55.2 \%)$ students, among whom girls predominated (10 people or 62.5\%). Subsequent studies have shown that a significant number of students with latent iron deficiency showed moderate signs of decreased cognition. Conclusions: 1. The frequency of latent iron deficiency in the surveyed contingent was $8.5 \%$, with an absolute predominance of girls (62.5\%). 2. Latent iron deficiency in student youth can be manifested by cognitive impairment, and therefore affect academic performance. 3. The most pronounced correlation was found for ferritin content and severity of alexithymia $(r=-0.61)$.

Key words: latent iron deficiency; cognitive abilities; alexithymia; nutrition; student youth

Iron deficiency is the most common alimentary deficiency in the world $[1,2]$. All groups of the population are vulnerable, but young women, infants and toddlers are in the highest risk [1-3]. Young women have an increased need for iron due to constant losses during menstruation, as well as during pregnancy and lactation. Up to two-thirds of young women in developing countries suffer from iron deficiency [1, 3, 4]. However, this phenomenon is also observed in economically developed countries - from $10 \%$ to $20 \%$ in the US and EU $[3,5,6]$. The exact epidemiology of iron deficiency among young women in the post-Soviet countries is unknown [7,8], but given the significant deterioration of the socioeconomic status of ordinary citizens, it can be assumed that the incidence of iron deficiency is close to third world levels.

As a rule, the cases of manifested iron deficiency fall into the field of view of doctors. But latent iron deficiency is much more common. This condition is characterized by dicreased level of ferritin in the serum (less than $20 \mu \mathrm{g} / \mathrm{l}$ ) whiled hemoglobin level is higher than $120 \mathrm{~g} / \mathrm{l}$ $[1,2,9,10]$.

There is currently evidence of an association between iron deficiency and cognitive impairment [11-13]. The exact mechanism by which iron deficiency affects the brain is poorly understood. There are possible disorders in the metabolism of neurotransmitters, decreased myelin formation and changes in energy metabolism of the brain [1, 11].

Some authors point to an association between the use of iron-containing nutraceuticals and improved cognitive function in young women, but the results are largely debatable, as the vast majority of these studies have corrected overt iron deficiency [12, 13]. Instead, it is still 
unknown what affects the presence of latent iron deficiency on the cognitive abilities of young people, including students.

It is known that the eating habits of student youth often do not meet the principles of healthy eating. Students prefer snacks and fast food products, often do not have a full lunch and breakfast, as a result, most of the food is consumed during the supper, which can be very late $[7,8]$. It is also important to spread uncontrolled use of the medications that may affect iron metabolism, including nonsteroidal anti-inflammatory drugs, antacids, histamine receptor antagonists, proton pump inhibitors, corticosteroids and antibiotics) [14, 15].

The aim of the study is to assess the impact of latent iron deficiency on students' cognitive abilities

\section{Material and methods}

The study was conducted during 2018-2021 at the Department of Hygiene and Medical Ecology of Odessa National Medical University. A survey of 188 medical students aged 18-20 years, who were interviewed using the original tool [7], which contained questions about the quality of the daily diet, the presence of manifestations of sideropenic syndrome, and separate section for girls about menstruation functions

Estimation of the qualitative content of iron compounds in the diet was performed by a calculation method using the USDA/FDA database [16]. Persons with probable iron deficiency were examined for hemoglobin, erythrocytes, hematocrit and serum ferritin. Analytical research was performed in the accredited laboratory "Smartlab" (Odessa). General blood tests were performed on an automatic hematology analyzer CELL-DYN Ruby "Abbott laboratories" (USA), ferritin analysis - on an automatic chemiluminescent analyzer Architect I1000sr "Abbott laboratories" (USA).

Additionally, the assessment of cognitive abilities of persons with latent iron deficiency was assessed. We used a battery of tests, which included methods of assessing attention, memory, visual-spatial perception, planning, execution, logical thinking, ability to abstract, emotional response, level of alexithymia, namely the methods of MocA, TMT, GPB , Schulte tables and TAS-20 [17-21]. As a control, 30 students aged 18-20 years who showed no signs of latent or overt iron deficiency were interviewed.

Statistical processing was performed by methods of variance and correlation anamnesis using the software Statistica 13.0 (TIBCO, USA) [22].

Results. When evaluating diets, probable iron deficiency was identified in $69(36.7 \%)$ students surveyed. A significant number of students reported signs of iron deficiency, namely general weakness (27 or $14.4 \%$ ), increased fatigue (30 cases or $15.9 \%$ ), pale skin and mucous 
membranes (6 or $3.2 \%$ ), drowsiness ( 8 or $4.3 \%$ ), dry mouth (11 or $5.9 \%$ ), brittle hair (4 or $2.1 \%$ ), bleeding gums (3 or $1.6 \%$ ). In isolated cases, hyposmia, dysgeusia and dysphagia have occurred.

Probable iron deficiency was found at the previous stage of the study in $29(15.4 \%)$ patients, they subsequently underwent verifying laboratory tests. In the analysis of the obtained data, the diagnosis of mild iron deficiency anemia was confirmed in 2 (6.9\%) girls. Latent iron deficiency was identified in 16 (55.2\%) students, among whom girls predominated (10 people or $62.5 \%)$.

Subsequent studies found that a significant number of students with latent iron deficiency showed moderate signs of decreased cognition (Table 1). At the same time, the most significant changes were observed in the indicators of attention quality, working memory and alexithymia.

Table 1 The results of neuropsychological testing

\begin{tabular}{|c|c|c|c|c|}
\hline \multirow{2}{*}{\multicolumn{2}{|c|}{ Tests }} & \multicolumn{2}{|c|}{ Indices } & \multirow[t]{2}{*}{ Reference levels } \\
\hline & & $\begin{array}{c}\text { Basic group } \\
(n=29)\end{array}$ & $\begin{array}{c}\text { Control group } \\
(n=30)\end{array}$ & \\
\hline \multicolumn{2}{|c|}{ MoCA, points } & $26,2 \pm 1,2$ & $26,9 \pm 0,8$ & More than 26 points [17] \\
\hline \multicolumn{2}{|c|}{ TMT, sec } & $76,3 \pm 4,3$ & $70,1 \pm 2,2$ & $29-78 \mathrm{sec}[18]$ \\
\hline \multirow[t]{2}{*}{ GPB, sec } & Dominated limb & $77,6 \pm 4,1^{*}$ & $65,8 \pm 1,4$ & $\leq 70 \mathrm{sec}$ \\
\hline & $\begin{array}{l}\text { Non-dominated } \\
\text { limb }\end{array}$ & $85,7 \pm 4,5^{*}$ & $74,8 \pm 2,2$ & $\leq 100 \mathrm{sec}[19]$ \\
\hline \multicolumn{2}{|c|}{ Shulte's tables, sec } & $149,2 \pm 11,4$ & $137,3 \pm 5,2$ & $30-50$ sec per a table [20] \\
\hline \multicolumn{2}{|c|}{ TAS-20, points } & $59,5 \pm 1,7 *$ & $55,2 \pm 1,1$ & $\leq 62$ points \\
\hline
\end{tabular}

Note: $*$ - differences between groups are significant $(\mathrm{p}<0,05)$

As can be seen from the table, almost half of the surveyed students, in the presence of latent iron deficiency had worse than the normative test results. At the same time, for most tests, no statistically significant differences with control were observed. Exceptions were the values of the test for alexithymia $(59.5 \pm 1.7$ points in the main group and $55.2 \pm 1.1$ points in the control group), as well as the results of tests for dexterization of movements (for the dominant limb $77.6 \pm 4.1 \mathrm{~s}$ in the main group and $65.8 \pm 1.4 \mathrm{~s}-$ in the control, for nondominant $-85.7 \pm 4.5 \mathrm{~s}$ and $74.8 \pm 2.2 \mathrm{~s}$, respectively).

When comparing the obtained data of neuropsychological testing, the presence of a significant correlation between the obtained indicators and the level of ferritin was determined (Fig. 1). 


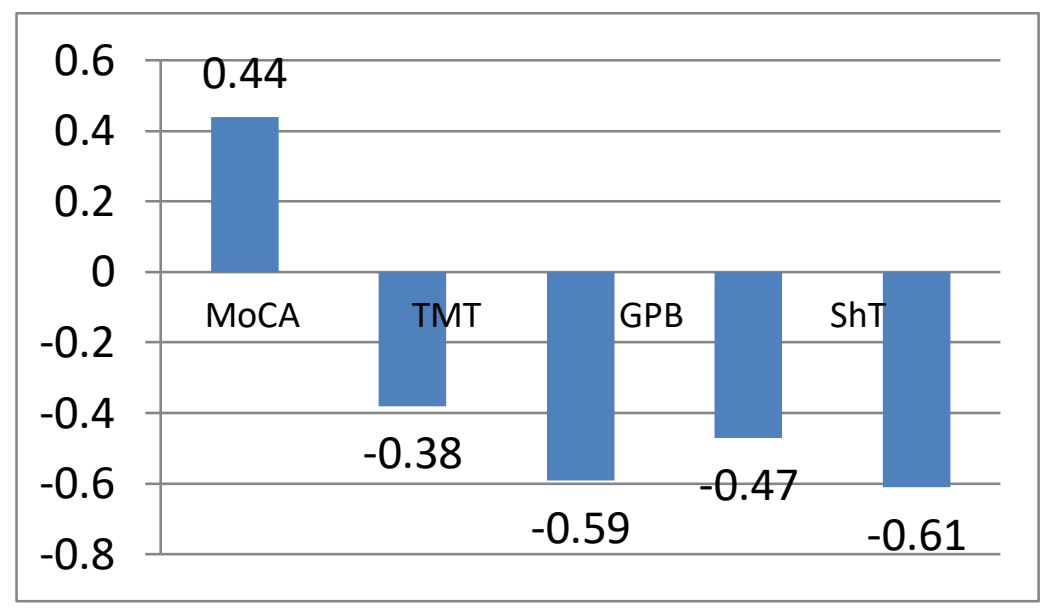

Figure 1. Correlation between ferritin levels and test results

Thus, for most of the used neuropsychological techniques, the correlation with the content of ferritin is inverse, the only exception is the assessment of the Montreal scale of assessment of cognitive functions.

\section{Discussion}

All, without exception, known studies of the impact of iron deficiency on cognitive functions are characterized by great heterogeneity in the methods used for cognitive testing and the contingents of respondents. The general trends identified in most studies are the close relationship between the severity of sideropenic syndrome and associated asthenia and the level of cognitive ability.

Differences in the effects of iron deficiency on cognitive function reported between studies may be related to the different cognition assessment tools used. At the same time, there is a growing number of publications in which the authors use cognitive testing to prove the feasibility of using dietary supplements containing iron salts to improve resistance to stress and cognitive abilities in general.

Of particular interest are studies of the impact of iron deficiency on the severity of alexithymia, which means a deficiency of cognitive processing and emotional regulation [21], which leads to difficulties in identifying feelings and separating them from purely bodily sensations. Alexithymia is characterized by the complexity of describing subjective feelings, limited image processes, lack of imagination and lack of adequate response to habitual stimuli with changes in cognitive style $[21,23]$. Patients report an inability to adequately identify physical sensations as somatic manifestations of emotions. Some studies have discussed the likely impact of iron deficiency on the functioning of the hippocampus and other functionally important areas of the brain. Thus, Allen M et al. (2017) showed that the concentration of 
microstructural iron in the somatosensory cortex is accompanied by increased cognitive empathy, while the tendency to experience negative emotions is mostly associated with the myeloarchitecture of the islet and caudate nucleus [24].

\section{Conclusions}

1. The frequency of latent iron deficiency in the surveyed contingent was $8.5 \%$, with an absolute predominance of girls $(62.5 \%)$

2. Latent iron deficiency in student youth can be manifested by cognitive impairment, and therefore affect academic performance

3. The most pronounced correlation was found for ferritin content and severity of alexithymia $(\mathrm{r}=-0.61)$

\section{References:}

1. Stoltzfus RJ. Iron deficiency: global prevalence and consequences. Food Nutr Bull. 2003 Dec;24(4 Suppl):S99-103. doi: 10.1177/15648265030244S206. PMID: 17016951.

2. Alshwaiyat NM, Ahmad A, Wan Hassan WMR, Al-Jamal HAN. Association between obesity and iron deficiency (Review). Exp Ther Med. 2021 Nov;22(5):1268. doi: 10.3892/etm.2021.10703. Epub 2021 Sep 7. PMID: 34594405; PMCID: PMC8456489.

3. Gattermann N, Muckenthaler M, Kulozik AE, Metzgeroth G, Hastka J. The Evaluation Of Iron Deficiency And Iron Overload. Dtsch Arztebl Int. 2021 Dec 10; (Forthcoming): arztebl.m2021.0290. doi:10.3238/arztebl.m2021.0290. Epub ahead of print. PMID: 34755596.

4. Turawa E, Awotiwon O, Dhansay MA, Cois A, Labadarios D, Bradshaw D, Pillay-van Wyk V. Prevalence of Anaemia, Iron Deficiency, and Iron Deficiency Anaemia in Women of Reproductive Age and Children under 5 Years of Age in South Africa (19972021): A Systematic Review. Int J Environ Res Public Health. 2021 Dec 4;18(23):12799. doi: 10.3390/ijerph182312799. PMID: 34886524; PMCID: PMC8656986.

5. Eiduson R, Heeney MM, Kao PC, London WB, Fleming MD, Shrier LA. Prevalence and Predictors of Iron Deficiency in Adolescent and Young Adult Outpatients: Implications for Screening. Clin Pediatr (Phila). 2022 Jan;61(1):66-75. doi: 10.1177/00099228211059647. Epub 2021 Nov 19. PMID: 34796723.

6. Ntahe A, Serror K, Boccara D, Chaouat M, Mimoun M, Plaud B. Iron status in 1041 non-anaemic patients scheduled for elective reduction mammoplasty: prevalence of iron depletion, iron deficiency, and low iron stores. Br J Anaesth. 2021 Dec;127(6):e207-e210. doi: 10.1016/j.bja.2021.09.011. Epub 2021 Oct 15. PMID: 34657663. 
7. Ancheva I. A., Babienko V. V., Sheikh A. D., Ivanko O. M. Alimentary factor of providing the body of a pregnant woman with iron // Modern problems of hygiene, radiation and environmental medicine.. 2016. № 6. P. 11-18.

8. Gutareva N. V., Yakovenko V. G., Gutarev V. V., Yablochanskaya E. E. Iron deficiency anemia: basic diagnostic, therapeutic and preventive approaches Ukrainian Journal of Medicine, Biology and Sport - № 4 (6) 142-147

9. Lynch S, Pfeiffer CM, Georgieff MK, et al. Biomarkers of Nutrition for Development (BOND)-Iron Review. J Nutr. 2018;148(suppl_1):1001S-1067S. doi:10.1093/jn/nxx036

10. USDA/FDA Database. Електронний ресурс. Режим доступу: https://fdc.nal.usda.gov

11. Blanco-Campal A, Diaz-Orueta U, Navarro-Prados AB, Burke T, Libon DJ, Lamar M. Features and psychometric properties of the Montreal Cognitive Assessment: Review and proposal of a process-based approach version (MoCA-PA). Appl Neuropsychol Adult. 2021 Nov-Dec;28(6):658-672. doi: 10.1080/23279095.2019.1681996. Epub 2019 Nov 12. PMID: 31718290.

12. Sakai H, Furui A, Hama S, Yanagawa A, Kubo K, Morisako Y, Orino Y, Hamai M, Fujita K, Mizuguchi T, Kandori A, Tsuji T. Pen-point Trajectory Analysis During Trail Making Test Based on a Time Base Generator Model. Annu Int Conf IEEE Eng Med Biol Soc. 2021 Nov;2021:6215-6219. doi: 10.1109/EMBC46164.2021.9629991. PMID: 34892535.

13. Heintz Walters B, Huddleston WE, O'Connor K, Wang J, Hoeger Bement M, Keenan KG. The role of eye movements, attention, and hand movements on age-related differences in pegboard tests. J Neurophysiol. 2021 Nov 1;126(5):1710-1722. doi: 10.1152/jn.00629.2020. Epub 2021 Oct 13. PMID: 34644180.

14. Khramova MV, Kuc AK, Maksimenko VA, Frolov NS, Grubov VV, Kurkin SA, Pisarchik AN, Shusharina NN, Fedorov AA, Hramov AE. Monitoring the Cortical Activity of Children and Adults during Cognitive Task Completion. Sensors (Basel). 2021 Sep 8;21(18):6021. doi: 10.3390/s21186021. PMID: 34577225; PMCID: PMC8472204.

15. Lemche AV, Chaban OS, Lemche E. Alexithymia as a risk factor for type 2 diabetes mellitus in the metabolic syndrome: a cross-sectional study. Psychiatry Res. 2014 Feb 28;215(2):438-43. doi: 10.1016/j.psychres.2013.12.004. Epub 2013 Dec 14. PMID: 24388726. 
16. Leonard AJ, Chalmers KA, Collins CE, Patterson AJ. A study of the effects of latent iron deficiency on measures of cognition: a pilot randomised controlled trial of iron supplementation in young women. Nutrients. 2014;6(6):2419-2435. Published 2014 Jun 23. doi:10.3390/nu6062419

17. MoCA test. Retrieved from: https://www.mocatest.org

18. Trail Making Test (TMT) Parts A \& B. Retrieved from: http://apps.usd.edu/coglab/schieber/psyc423/pdf/IowaTrailMaking.pdf

19. Grooved pegboard test user instructions. Retrieved from: https://www.advys.be/docs/GroovedPegboardTestManual.pdf

20. Attention tests "Schulte tables". Retrieved from: https://metodorf.com/tests/schulte tables.php

21. Schroeders U, Kubera F, Gnambs T. The Structure of the Toronto Alexithymia Scale (TAS-20): A Meta-Analytic Confirmatory Factor Analysis. Assessment. July 2021. doi:10.1177/10731911211033894

22. Borovikov V.P. A popular introduction to modern data analysis and machine learning at Statistica St. Petersburg, $2016-354$ p.

23. Robin M, Belbèze J, Pham-Scottez A, et al. Paradoxes in Borderline Emotional Dysregulation in Adolescence: Influence of Parenting, Stressful Life Events, and Attachment. Front Psychiatry. 2021;12:735615. Published 2021 Oct 21. doi:10.3389/fpsyt.2021.735615

24. Allen, M., Frank, D., Glen, J. et al. Insula and somatosensory cortical myelination and iron markers underlie individual differences in empathy. Sci Rep 7, 43316 (2017). https://doi.org/10.1038/srep43316 